\title{
Rubber Strap Quality Improvement by Optimization of Tensile Strength and Time Curing Using Response Surface Methodology
}

\author{
Jefri Erwanto $^{1}$ and Mok. Su'ef ${ }^{1}$
}

\begin{abstract}
This paper will demonstrate combination of optimum response for Tensile strength and Time curing which are obtained by combining elastomer, filler and co-accelerator at optimum level factors is the best way to overcome defect products. Data from this study will be obtained from 15 direct experiments based on RSM by using box-behnken designMinitab 18 and response optimization was performed to get optimal response value combination from the expected target response. The analysis shows that all factors including elastomer, filler and co-accelerator have significant effect on tensile strength and time curing responses. The best composition to get the optimal combination of responses from certain response limits is elastomer $=70 \mathrm{PHR}$, filler $=30 \mathrm{PHR}$, and co-accelerator $=1.47 \mathrm{PHR}$. The optimum value for tensile strength response is $15 \mathrm{~kg} / \mathrm{cm} 2$ and time curing is 3.5 minutes. Beside as a solution for this problem, this optimization will increase production capacity of rubber strap $12.5 \%$ more that the factory decide to decrease production line and choose market development strategy to overcome access production and labor to new product base on polyurethane.
\end{abstract}

Keywords-Optimization, Tensile Strength, Time Curing, Response Surface Methodology, Box-behnken, Regression Analysis.

\section{INTRODUCTION}

The tightly competition in the footwear industry, especially flip-flops, makes every manufacturer of flipflops have to maintain the quality, price and availability of goods well, so they can compete with competitors in the flip-flops market. One way that can be chosen in winning the competition is to minimize production defects. With the lack of defective products, it makes high production efficiency so that it does not cause other costs that add to the burden included in the cost of goods sold.

The problem in the industry today is still there are several products that have a low tensile strength $(<12 \mathrm{~kg} /$ $\mathrm{cm} 2$ ) so that in the assembling process with the tread section, the rubber strap breaks up with a low load pull. The distribution data of observations of tensile strength in the rubber strap production process can be seen in Table 1 .

\footnotetext{
${ }^{1}$ Jefri Erwanto and Mok. Su'ef are with Department of Industrial Management, Institut Teknologi Sepuluh Nopember, Surabaya, 60111, Indonesia.Email: jefrierw@gmail.com; m_suef@ie.its.ac.id.
}

This condition will decrease the benefit of the company because in terms of raw materials, there must be a process of remanufacturing rubber strap and also the process of releasing the broken rubber strap from the site which takes a long time. With the completion of this problem, it will reduce costs due to the breakdown of rubber strap that have an impact on decreasing cost of goods sold (COGS) so as to increase the company's competitiveness.

TABLE 1.

Distribution Data of TENSILE STRENGTH TEST RESUlts

\begin{tabular}{ccll}
\hline \hline \multirow{2}{*}{ Period } & \multicolumn{3}{c}{ (Tensile Strength $-\mathrm{kg} / \mathrm{cm} 2)$} \\
& $<12$ & Dec-14 & \multicolumn{1}{c}{$>14$} \\
\hline October'18 & $1.70 \%$ & $67.30 \%$ & $31 \%$ \\
Nopember'18 & $1.50 \%$ & $61 \%$ & $37.50 \%$ \\
December'18 & $1.90 \%$ & $55.10 \%$ & $43 \%$ \\
\hline \hline
\end{tabular}

Solving this problem the company must know the factors of the composition of materials that have an influence on the tensile strength produced. Tensile strength is one of the basic properties of the most important polymer material and is often used to characterize a polymer material. The tensile strength of a material is defined as the maximum load size (Fmax) used to decide the specimen of the material divided by the initial cross-sectional area (Ao) as an equation 1 below:

$$
\begin{aligned}
& \sigma=\frac{F \text { maks }}{A 0} \\
\sigma \quad & \text { tensile strength }(\mathrm{kgf} / \mathrm{mm} 2) \mathrm{F} \text { max }=\text { maximum } \\
& \text { load }(\mathrm{kgf}) \\
\text { Ao } \quad & \text { initial cross-sectional area }(\mathrm{mm} 2)
\end{aligned}
$$

Another factor that is also influential is time curing 90. Time Curing is the time needed from the beginning of the warm up to ripen the compound to optimum maturity[1]. Curing process on rubber compound is divided into 3 timebased phases, Three main regions are specified in this figure: first, the induction: in this region the rubber sample is put into the heated cavity of the rheometer and its shear modulus drops due to softening of the compound[2], however, the cross-links have not yet been formed. Next, the cure stage, where crosslinking takes place within the rubber compound. As a result of forming three dimensional 
cross-linked networks, the elasticity and tensile strength of the rubber is improved which results in the increasing trend of the torque curve. Finally, the post- cure, where the torque decreases or remains constant depending on the specific cure sys- tem[3]. Since the post-cure step usually has an undesirable effect on quality and physical properties of the final product, it becomes necessary to optimize the curing process[4].

The three time-based phases are shown in the following Figure 1:

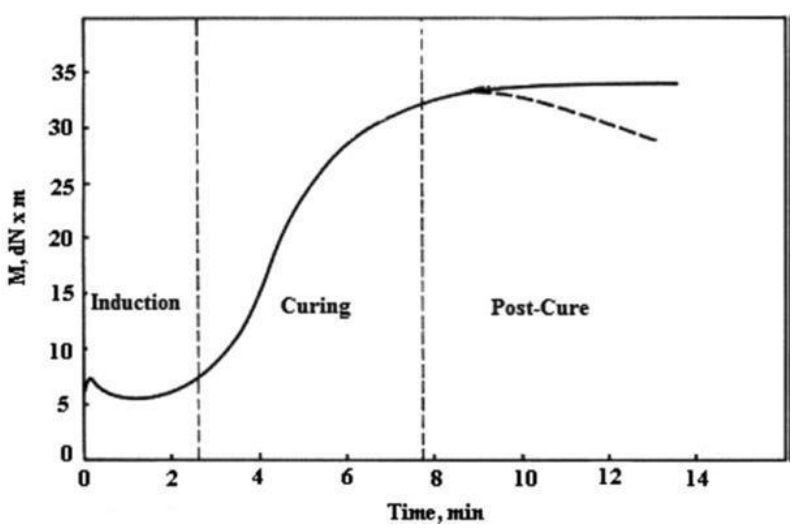

Figure 1.3 phase of Curing time

Moving Die Rheometer (MDR) is an experimental tool that is widely used to determine the maturity curve of a rubber compound. The standard shape dimensions of the rubber sample are given in Figure 2.18 below:

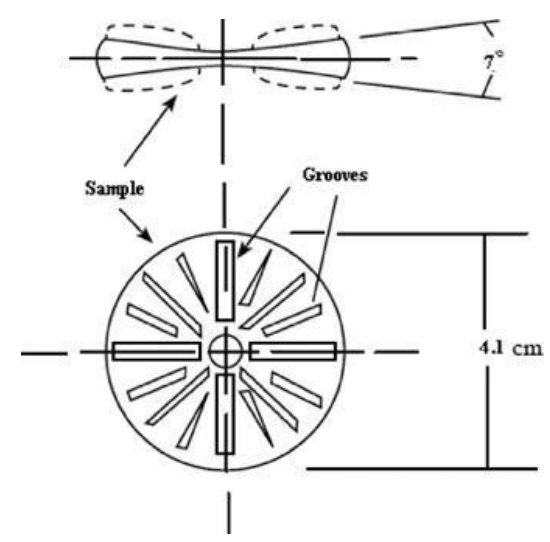

Figure 2. Dimensions of the standard shape of a rubber sample

The sample is located between two heated plates where the lower one oscillates sinusoidally. The MDR instrument measures the torque response of rubber samples during the maturity test process based on ASTM D5289[5].

From the optimization of the two responses above, it is expected to be able to obtain the exact composition of the amount of elastomer, filler and co-accelerator so that it can produce 90 Time curing output and optimal tensile structure, knowing the price of compound in optimum composition and characteristics and comparison when compared with the compound price used for the rubber strap production process, knowing the amount of savings that can be done by increasing the quality of the rubber strap tensile test with the formulation optimization that has been done.

The design of experiment (DOE) allows multiple input factors manipulation to determine their effects on the desired output (response). By manipulating multiple inputs at the same time, DOE can identify important interactions that may be neglected when experimenting with one factor at a time. All possible combinations can be investigated (full factorial) or only a portion of the possible combinations (fractional factorial)[6].

The aspect DOE can be achieved by response surface methodology (RSM). RSM is the process of collecting the statistical and mathematical techniques which are useful for analysis and modeling in the applications where the concerned response is influenced by some variables[7].

RSM coupled with Box-Behnken design (RSM- BBD) is selected for the current study due to its: (1) ability to process multiple variables; (2) capability of evaluating the interactions between factors; (3) avoidance of extreme conditions; and (4) less resource demand[8].

\section{METHOD}

325 mesh filler type of Calcium Carbonate material from Omya Carb Indonesia as fillers which function to improve the physical properties of rubber, Titanium dioxide by the type of Anatase as a co-accelerator that function to accelerate the vulcanization reaction of rubber (rubber maturity) because the compound which only contains vulcanization material only the maturation of the rubber is still very slow and requires a large amount of vulcanization material, high temperature, Standart Indonesia Rubber 20BROWN 2X and RSS 1 as the type of Natural rubber use as an elastomer. Natural rubber still become the best elastomer because natural rubber is capable of rapid deformation and recovery along with strain crystallization[9]. It also exhibits outstanding characteristics such as good hysteretic properties, high tear strength, high tensile strength, and high green strength[10]. Sulfur as a vulcanizing agent that convert free rubber molecules into one three-dimensional network through the formation of cross bonds, antidegrdant material as a rubber protective material from outside influences that can cause degradation because rrrubber whose molecules have double bonds is easily handed over by oxygen and ozone, aktivator by combining Zinc Oxide and Stearic Acid, prevulacanization inhibitor to prevent scorching in hot press processing and pigment added in rubber compounds that function as colors.

Fisrt all of the experimental procedure is mastication, to reduce the viscosity or molecular weight of the rubber. The shear force arising from two rotating rotors breaks the 
bonds (chains) of the rubber molecules so that the breakdown of the molecular bonds allows carbon and other chemicals to bind to the rubber .

All ingredients are mixed in a kneader close mixer for 5 minutes starting from material with large size and hard. the mixture or compound will enter into an 8 inch diameter open roll mill machine for calendering process, in the calendering process compound are cutted off accordance with the expected dimensions. Expected dimension depend on the product need, the larger of product size, the larger of the sheet dimension then sheet will get coating by nonsticky substance for each sheet which is finished from the open roll mill machine. The factor level chosen as shown in Table 2.:

TABLE 2.

FACTORS AND LEVEL FACTORS USED IN THE STUDY

\begin{tabular}{cccc}
\hline \hline Factor & $\begin{array}{c}\text { Lower central } \\
\text { limit }\end{array}$ & central limit & $\begin{array}{c}\text { Upper central } \\
\text { limit }\end{array}$ \\
\hline elastomer & BROWN 2X & BROWN & BROWN 2X \\
filler & $30 \mathrm{PHR}$ & $2 \mathrm{X} 65 \mathrm{PHR}$ & $100 \mathrm{PHR}$ \\
Co-accelerator & $0.5 \mathrm{PHR}$ & $60 \mathrm{PHR}$ & $90 \mathrm{PHR}$ \\
\hline \hline
\end{tabular}

The experimental design chosen for conducting the experiment in this study was the Box-Behnken trial design. This model is an optimal design for viewing or getting responses with a large number of variables without conducting many experiments. This can be seen from the number of trials carried out, only 15 (fifteen) times of experimentation with different treatments.

With experiments that are relatively few in number do not cause the experimental results to be invalid. This is because according to Box-Behnken with 15 trials with different treatments consisting of 12 times the experiments conducted at the upper, middle and lower levels plus the same three times the experiment at the middle level is enough to know the desired response results.

Experiments were carried out at the Formulation Laboratory at a sandals manufacturing company held in Indonesia using the multiple surface response method and box-behnken design. rubber strap compound made in relatively small quantities, namely the scale of laboratory tests with processes relevant to the rubber manufacturing process on a mass production scale.

The response data obtained from the experiment, namely Tensile Strength, was obtained using Tensomete and Time Curing 90, obtained by using a Rheometer. The two data above are processed using Minitab 18 software.

Setting goal for Time Curing 90 is the target is best. For this option the target value, lower bound and upper bound are set. Determination of upper bound value refers to company standards.

- Target value (target value) $=3.5$ minutes
- Lower bound

$$
=3 \text { minutes }
$$$$
=4 \text { minutes }
$$

- Upper bound

Setting goal for Tensile strength is the target is best. For this option the target value and upper bound are set. Determination of lower bound values refers to company standards.

- Target value $=15 \mathrm{~kg} / \mathrm{cm} 2$

- Lower limit value (normal value)

- Lower bound $=14 \mathrm{~kg} / \mathrm{cm} 2$ $=18 \mathrm{~kg} / \mathrm{cm} 2$

After obtaining the optimal response value, to find out the accuration of the result analysis, a confirmation experiment is conducted. Confirmation experiments were carried out 3 (three) times at the level of factors that produced the optimal response, then calculated the compound price at the optimum composition compared to the price of the compound being used for the rubber strap production process.

\section{RESULT AND DisCUSSION}

The experiment was based on the Box-Behnken design which carried out 15 (fifteen) variables with different and random treatments, with different compositions of filler, elastomer and Co-accelerator content, and repetitions of the middle values three times. Experimental results are shown in Table 3:

TABLE 3.

EXPERIMENTAL RESULTS USING BOX-BEHNKEN DESIGN

\begin{tabular}{|c|c|c|c|c|}
\hline \multicolumn{3}{|c|}{ UNCODED } & \multirow{2}{*}{$\begin{array}{l}\text { Tensile } \\
\text { Strength }\end{array}$} & \multirow{2}{*}{$\begin{array}{l}\text { Time } \\
\text { Curing }\end{array}$} \\
\hline Elastomer & Filler & Co-Accelerator & & \\
\hline 65 & 60 & 1 & 14.5 & 3.5 \\
\hline 30 & 60 & 0.5 & 12.9 & 3.2 \\
\hline 30 & 60 & 1.5 & 13.1 & 3.1 \\
\hline 65 & 30 & 1.5 & 14.4 & 3.3 \\
\hline 65 & 90 & 0.5 & 13.2 & 3.2 \\
\hline 100 & 60 & 1.5 & 18 & 4.5 \\
\hline 30 & 90 & 1 & 12.1 & 3 \\
\hline 65 & 30 & 0.5 & 14.9 & 3.7 \\
\hline 100 & 30 & 1 & 18.7 & 4.5 \\
\hline 65 & 90 & 1 & 16.6 & 4.1 \\
\hline 30 & 60 & 1 & 14.4 & 3.5 \\
\hline 100 & 60 & 0.5 & 17.4 & 4.3 \\
\hline 65 & 90 & 1.5 & 14.1 & 3.3 \\
\hline 30 & 30 & 1 & 13.2 & 3.2 \\
\hline 65 & 60 & 1 & 14.5 & 3.6 \\
\hline
\end{tabular}

A. Regression Analysis for Tensile Strength Response

The $\mathrm{P}$ value in the far right column can be used to conclude whether $\mathrm{H}_{0}$ is accepted or rejected, by comparing the value of $\alpha=0.05$. If the value of $\mathrm{P}<\alpha$ means that the material variable has a significant effect on the Tensile stress response[11].

From Table 4. it can be seen that the $\mathrm{P}$ value for filler material $=0.006$, for elastomer $=0,000$ and for Coaccelerator $=0.002$, while $\mathrm{P}$ value for elastomeric elastomer, filler * filler and Co-accelerator * Coaccelerator is 0.002 respectively. ; 0.026; 0.039 which 
means that the three material factors have a significant effect on the Tensile stress response.

TABLE 4

RESUlt OF REGRESSION ANALYSIS FOR TENSILE STRENGTH RESPONSE Coded Coefficients

\begin{tabular}{lrrrr} 
Term & Coef & SE Coef & T-Value & P-Value \\
\hline Constant & 14.467 & 0.13 & 111.69 & 0.000 \\
Elastomer & 2.425 & 0.0793 & 30.57 & 0.000 \\
Filler & -0.65 & 0.0793 & -8.19 & 0.006 \\
CoAccelerator & 0.15 & 0.0793 & 1.89 & 0.002 \\
Elastomer*Elastomer & 0.942 & 0.117 & 8.07 & 0.002 \\
Filler*Filler & -0.258 & 0.117 & -2.21 & 0.026
\end{tabular}

Model Summary

\begin{tabular}{rrr} 
S & R-sq & R-sq(adj) \\
\hline 0.224351 & $99.55 \%$ & $98.73 \%$
\end{tabular}

The R-sq value is a value that shows the strong relationship between filler, elastomer and Co-accelerator with the Tensile stress response variable[12].

From the data in table 4.2 it can be seen that the value of $\mathrm{R}$-sq is $99.55 \%$, which means that the influence of all material variables on the response value is $99.55 \%$ and the remaining $0.045 \%$ is influenced by other variables besides the three material variables. estimate the value of the response variable.

TABLE 5.

RESUlts OF ANALysis Of VARIANCE For TENSILE STRENGTH RESPONSE Error

Lack-of-Fit

Pure Error

Total

\begin{tabular}{r|r|r|r|r}
5 & 0.03797 & 0.00759 & & \\
3 & 0.03672 & 0.01224 & 19.58 & 0.390 \\
2 & 0.00125 & 0.00062 & & \\
14 & 3.65608 & & &
\end{tabular}

The $\mathrm{P}$ value in table 4.3 is used in hypothesis testing to determine the significance of the regression model and to test whether there is a lack of fit. If $\mathrm{P}<\alpha(\alpha=0.05)$, then $\mathrm{H}_{0}$ is rejected, meaning that the regression model is significant to estimate the response[13].

In Table 4, it can be seen that the $\mathrm{P}$ value of the overall regression model $=0.000$, the linear regression model $=$ 0.000 and the square model $=0.000$, because the value of $\mathrm{P}$ $<0.05$ means the regression model is significant. As for the $\mathrm{P}$ value for the lack of fit test if the value of $\mathrm{P}<0.05$ means that $\mathrm{H}_{0}$ is rejected or there is lack of fit, if the value of $\mathrm{P}>$ 0.05 means $\mathrm{H}_{0}$ is accepted or there is no lack of fit. From Table 4 the $\mathrm{P}$ value for lack of fit $=0.390$ or $\mathrm{P}>0.05$, means that the resulting equation has no lack of fit and is sufficient.

The regression equation model for the Tensile strenghts response to the factors of filler, elastomer and $\mathrm{Co}$ accelerator material in coded are as follows:

$\hat{\mathrm{Y}}=13.79-0.0221_{\mathrm{x} 1}+0.0049_{\mathrm{x} 2}-1.00_{\mathrm{x} 3}+0.000769_{\mathrm{x} 12}-$ $0.000287_{\mathrm{x} 22}-0.233_{\mathrm{x} 32}-0.000238_{\mathrm{x} 1 \times 2}+0.00571_{\mathrm{x} 1 \times 3}+$ $0.02333_{\mathrm{x} 2 \mathrm{x}}$

$$
\begin{array}{ll}
\hat{\mathrm{Y}} & =\text { the predicted Tensile structure response } \\
\mathrm{X} 1 & =\text { filler ingredients in coded } \\
\mathrm{X} 2 & =\text { elastomeric content in coded } \\
\mathrm{X} 3 & =\text { Co-accelerator material in coded }
\end{array}
$$

B. Regression Analysis for Tensile Strength Response

TABLE 6.

RESUltS OF REGRESSION ANALYSIS FOR TIME CURING RESPONSES 90 Coded Coefficients

\begin{tabular}{lrrrr} 
Term & Coef & SE Coef & T-Value & P-Value \\
\hline Constant & 3.525 & 0.0503 & 70.06 & 0.000 \\
Elastomer & 0.6156 & 0.0308 & 19.98 & 0.000 \\
Filler & -0.1406 & 0.0308 & -4.56 & 0.006 \\
CoAccelerator & -0.0125 & 0.0308 & -0.41 & 0.007 \\
Elastomer*Elastomer & 0.275 & 0.0454 & 6.06 & 0.002 \\
Filler*Filler & -0.1125 & 0.0454 & -2.48 & 0.026 \\
CoAccelerator ${ }^{*}$ CoAccelerator & -0.0438 & 0.0454 & -0.96 & 0.037
\end{tabular}

Model Summary

$$
\begin{array}{rrr}
S & \text { R-sq } & \text { R-sq(adj) } \\
\hline 0.0871421 & 98.96 \% & 97.09 \%
\end{array}
$$

The $\mathrm{P}$ value for filler material $=0.006$, for elastomer $=$ 0,000 and for Co-accelerator $=0.072$, while the $\mathrm{P}$ value for elastomeric elastomer, filler $*$ filler and Co-accelerator $*$ Co-accelerator is 0.002 each; 0.026 ; 0.037 , which means that the three material factors have a significant effect on 90 Curing Time response.

The value of R-sq is a value that shows the strong relationship between filler, elastomer and Co-accelerator with Time Curing response variable 90. From the data in Table 5 it can be seen that the value of R-sq is $98.96 \%$, meaning the effect of all material variables on the change $98.96 \%$ and the remaining $1.04 \%$ is influenced by other variables besides the three material variables, thus the resulting regression equation is good for estimating the value of the response variable.

TABLE 7.

RESUltS OF ANALYSIS OF VARIANCE FOR TIME CURING RESPONSES 90

$\begin{array}{lrrrrr}\text { Error } & 5 & 0.03797 & 0.00759 & & \\ \text { Lack-of-Fit } & 3 & 0.03672 & 0.01224 & 19.58 & 0.094 \\ \text { Pure Error } & 2 & 0.00125 & 0.00062 & & \\ \text { Total } & 14 & 3.65608 & & & \end{array}$

The overall $\mathrm{P}$ regression model value $=0.000$, linear regression model $=0.000$ and square model $=0.006$, because the value of $\mathrm{P}<0.05$ means the regression model is significant. While the $\mathrm{P}$ value for lack of fit $=0.094$ or $\mathrm{P}>$ 0.05 , means that the resulting equation has no lack of fit and is sufficient.

The regression equation model for Time Curing 90 response to the factors of filler material, elastomer and Coaccelerator in coded are as follows:

$\hat{\mathrm{Y}}=3,552-0.01338 \mathrm{x} 1+0.00555 \times 2-0.355 \times 3+0.000224 \times 12-$ $0.000125_{\mathrm{x} 22}-0.175_{\mathrm{x} 32}-0.000036_{\mathrm{x} 1 \times 2}+0.00393_{\mathrm{x} 1 \times 3}+$ $0.00708_{\mathrm{x} 2 \times 3}$ 
$\hat{\mathrm{Y}} \quad=$ Predicted Time Curing 90 response

$\mathrm{x} 1=$ filler ingredients in coded

$\mathrm{x} 2=$ the content of the elastomer in coded

x3 $=$ Co-accelerator ingredients in coded

\section{Test for Residual Assumptions in Normal Distribution}

Normal examination and testing aims to determine whether the residual is normally distributed or not. This test can be done with the Kosmogorov-Smirnov test and make a residual graph. The formulation of the hypothesis is as follows:

$\mathrm{H}_{0}=$ Residual with normal distribution

$\mathrm{H}_{1}=$ Residuals are not normally distributed

By using the Minitab Software, the normal test results for the residual Tensile structure, as in Figure 3.

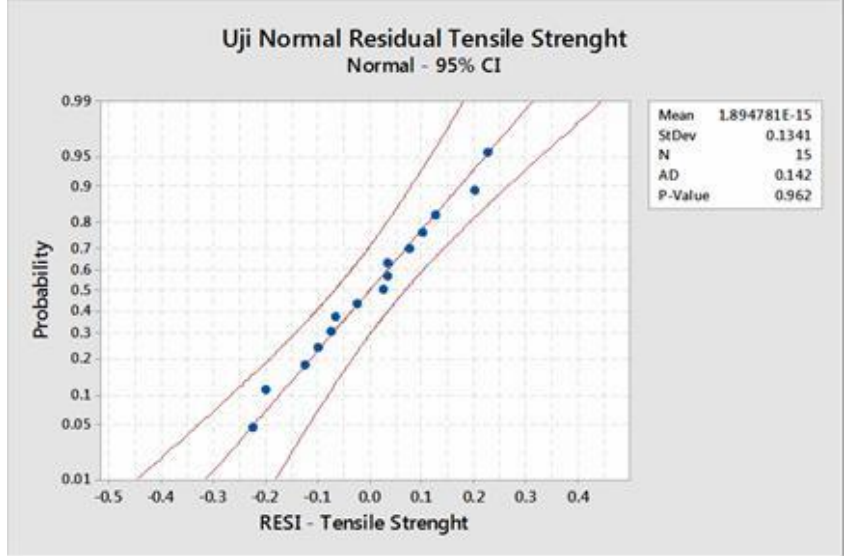

Figure 3. Normal Residual Test for Tensile Strength

From the test results it can be seen that Pvalue $=0.962$ or the value is greater than the value $\alpha=0.05$, then $\mathrm{H} 0$ is accepted so it can be concluded that the residuals for the Tensile stress regression equation are normally distributed. While the normal test results for Time Curing 90 are found in Figure 4.

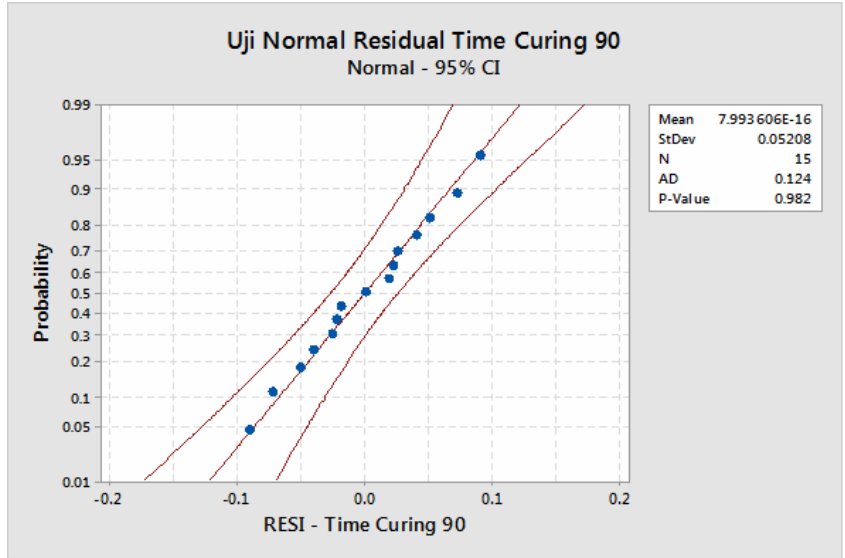

Figure 4 Normal Residual Test for Time Curing 90

From the picture above, it can be seen that Pvalue for the residual Time Curing 90 is 0.082 . Because the value is greater than the value of $\alpha=0.05$, then $\mathrm{H} 0$ is accepted so it can be concluded that the residuals for the Time Curing 90 regression equation are normally distributed.

\section{Independent Residual Assumption Test}

This test is conducted to determine the existence of independent pstraprties between the data obtained. Independent nature is a characteristic that must be controlled in an experiment with the aim that the data from one another is free. This test is done by looking at the ACF (Auto Correlation Function) graph.

Assumptions are declared independent if the residual correlation value is at intervals $(-2) / N_{n}$ and $(+2) / N_{n}$ From the test results $\mathrm{n}=15$ has fulfilled the independent assumption because the ACF value is at intervals of -0.516 and +0.516 as shown The Figure $5 \& 6$ :

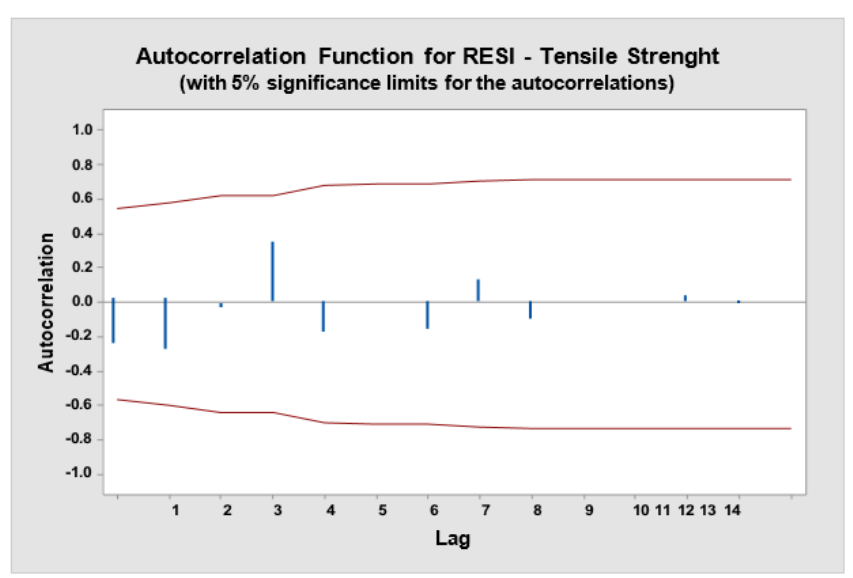

Figure 5. Graph of Autocorrelation for residual Tensile Strength

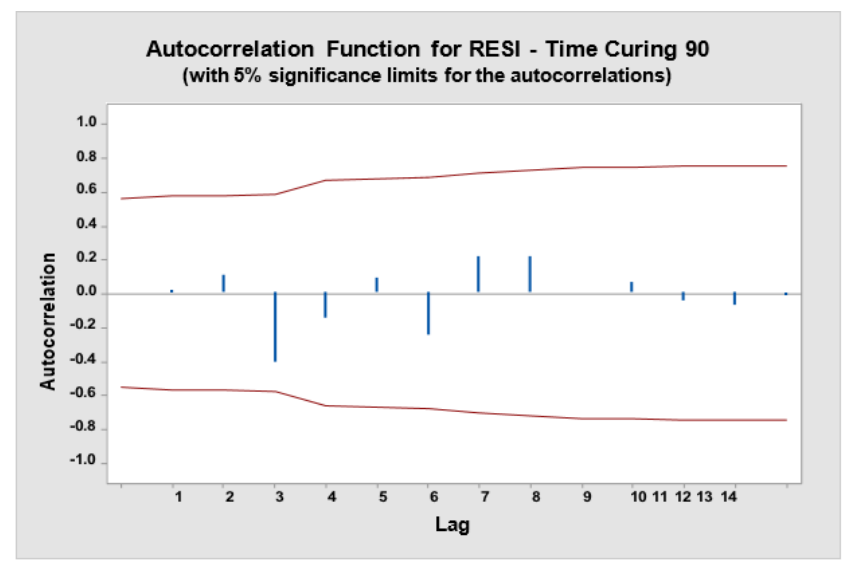

Figure 6. Graph of Autocorrelation for residual Time Curing 90

\section{E. Testing of Identical Assumptions}

Testing of identical assumptions can be done by making a plot (graph) between the residual and estimated values (FIT). This assumption is fulfilled if the data spread randomly around 0 and the plot does not form a certain pattern.

From the Minitab program, it can be seen that the test plots are identical assumptions, as in Figure $7 \& 8$. 


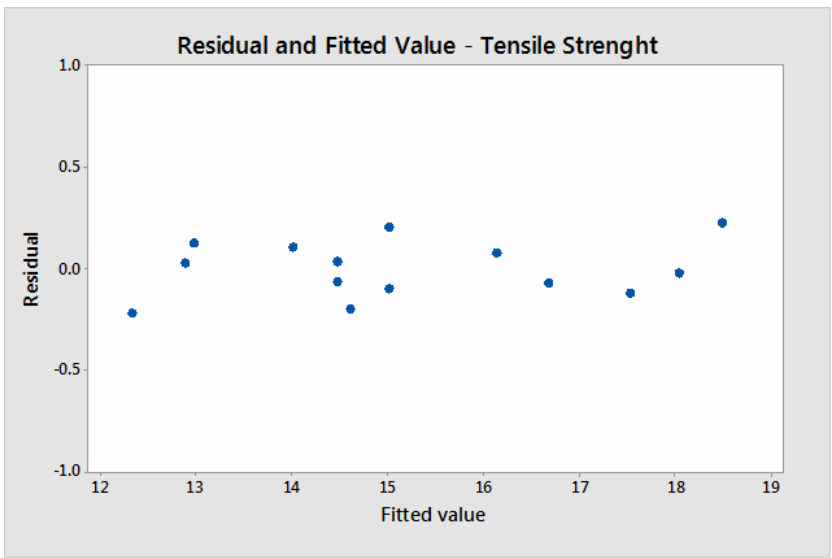

Figure 7. Residual Charts versus Fitted Values for Tensile Strength

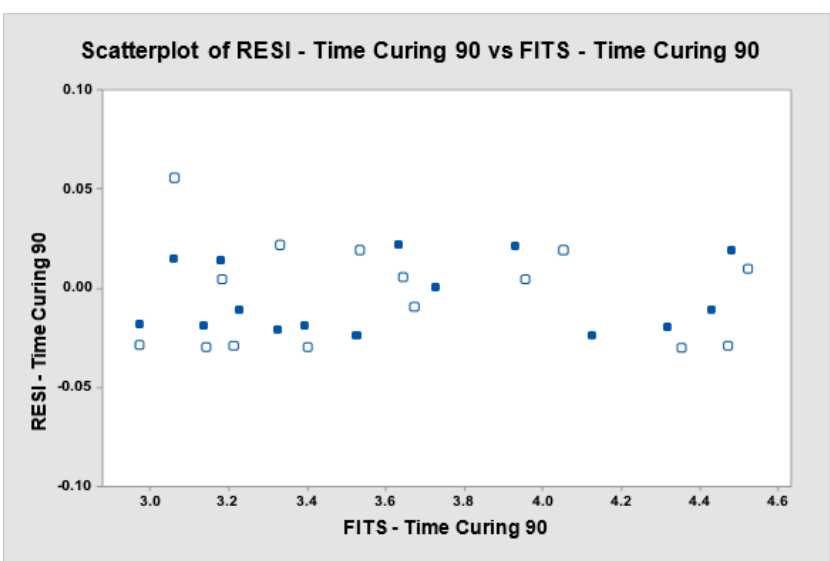

Figure 8. Residual Graph versus Fitted Value for Time Curing 90

From the test results in Figures 4.5 and 4.6 show that the pattern of residual data Tensile stress and Time Curing 90 is spread aaround 0 (zero), so it can be said that identical residual assumptions are fulfilled.

\section{F. Response Optimization}

The limit value selected for response optimization is shown in Table 8.

TABLE 8 .

LIMITATION OF RESPONSE OPTIMIZATION VALUES

\section{Parameters}

\begin{tabular}{llrrr} 
Response & Goal & Lower & Target & Upper \\
\hline Time Curing & Target & 3 & 3.5 & 4 \\
Tensile Strenght & Target & 14 & 15 & 18
\end{tabular}

From the processing of response optimization using Minitab 18 Software, the prediction of response value, global solution for material composition and desirability was obtained as shown in Figure 9 and the Table 9.
TABLE 9.

OPTIMIZATION RESULTS

Multiple Response Prediction

Solution

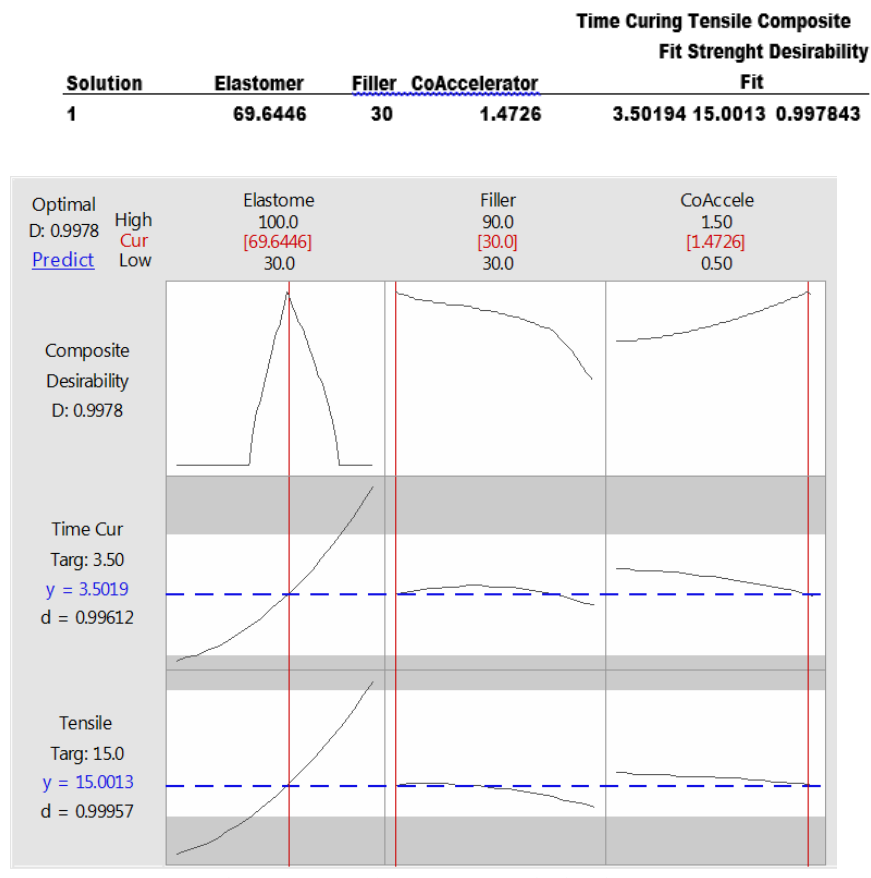

Figure 9. Graph response optimization

From the results of data processing shown in table 4.7 above, it can be seen that the desirability for Tensile structure $=0.999$, this means that the desired target Tensile strength can be achieved $99.9 \%$ desirability and for Time Curing $90=0.996$, this means that the desired target time curing 90 can be reached $99.6 \%$.

From the optimization results obtained the variable setting of materials as a factor under optimal conditions with the formulations as follows:

- Elastomer =69,645 PHR

- Filler $=30$ PHR

- Co - accelerator $=1,473$ PHR

The response predictions under optimal setting conditions are as follows:

- Tensile strength $=15,001 \mathrm{~kg} / \mathrm{cm}^{2}($ desirability $=0.999)$

- Time Curing $90=3,502$ minutes (desirability $=0.996$ )

Composite Desirability or combined desirability is 0.997.

\section{G. Surface Plots and Contour Plots from the Response}

Surface images and contour plots of the Time Curing 90 response equation can be seen by making one of the variables constant, for example filler $=60$ PHR (constant). As shown in Figure 10 and 11. 
The $1^{\text {st }}$ International Conference on Business and Management of Technology (IConBMT)

August 3rd 2019, Institut Teknologi Sepuluh Nopember, Surabaya, Indonesia

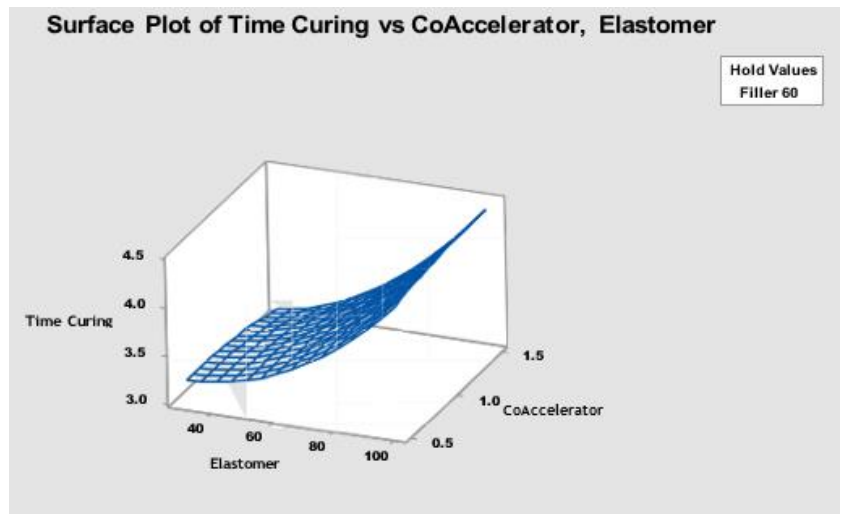

Figure 10. Surface plot for Time Curing response 90

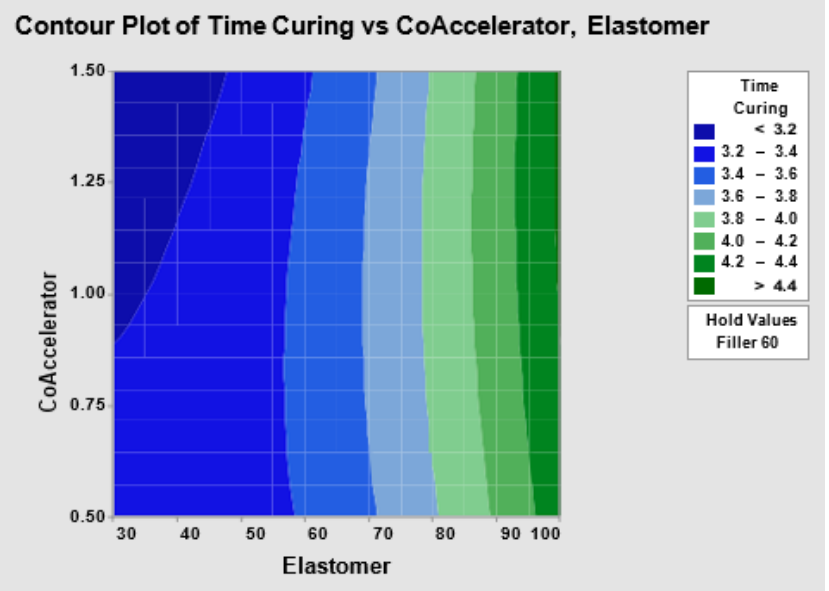

Figure 11. Contour plot for 90 Time Curing responses.

Figure 10 shows that in the state of constant filler variable $=60 \mathrm{PHR}$, the effect of changing the content of Co-accelerator has more effect on changes in the value of Time Curing 90 compared to changes in elastomer content. In Figure 11, it shows that the greater the contour layer of Time Curing 90 the greater.

\section{H. Calculation of Costs (prices) Compound}

Comparison of compound prices before and after optimization is done to determine the feasibility of the optimization results applied in the industry or not, even though the problem of not fulfilling the standard desired desired tensile strength value. This relates later to determining the cost of goods sold for a product.

Compound price data before and after optimization are given in Table 10.

TABLE 10.

COMPOUND PRICE CALCULATION

\begin{tabular}{cc}
\hline \hline \multicolumn{2}{c}{ Compound Price ( per kilogram ) } \\
\hline Before Optimization & After Optimization \\
\hline Rp 15.008 & Rp 17.870 \\
\hline \hline
\end{tabular}

From the data above there is an increase in the price of per-kilogram compound, from before the optimization of Rp. 15,008 to Rp. 17,870 after optimization. This is because there is a change in the use of raw materials as follows:

- Increasing the number of elastomeric formulations with better quality in the optimization compound.

- Decreasing the number of filler formulations in the optimization compound.

- Increasing the number of Co-Accelerator formulations on the optimization compound.

However, this does not make a significant price change that is expensive for the monthly production costs. This is because before the optimization of the product is broken during the assembly process and the operational costs are almost comparable when a comprehensive comparison is made. Total data on average monthly product production costs before and after optimization are given in Table 11.

TABLE 11.

Total Average Monthly Production Costs For The Product

\begin{tabular}{ll}
\hline \hline \multicolumn{2}{l}{ Total average monthly of production cost } \\
\hline Before Optimization & After Optimization \\
IDR 93,844,408.00 & IDR 93,073,403.43 \\
\hline \hline
\end{tabular}

\section{Calculation of production capacity}

The calculation of production capacity is done because with the results of the optimization that has been done there has been a change in Time Curing 90 which is used as a determination of the length of the hot press time in the production process. Production capacity data before and after optimization is given in Table 12.

TABLE 12.

CALCULATION OF PRODUCTION CAPACITY

\begin{tabular}{cc}
\hline \hline \multicolumn{2}{c}{ Time Curing 90 (minutes) } \\
\hline Before Optimization & After Optimization \\
\hline 4 & 3.5 \\
\hline \multicolumn{2}{c}{ Monthly capacity process (dozen) } \\
\hline Before Optimization & After Optimization \\
\hline 125000 & 140625 \\
\hline
\end{tabular}

From the data above, the increase in monthly production capacity from 125,000 Dozen to 140,625 Dozen. The increase in production capacity was $12.5 \%$. From the increase in production capacity the company will examine further whether it will continue to run the existing production system by adjusting the warehouse capacity of finished goods and sales targets or reducing production lines in proportion to the increase in production capacity.

As a result of the excess production capacity, the company will make adjustments to the production line and turn the excess resources into polyurethane-based products. This is a form of product development strategy. Product development is a growth strategy in which a business unit introduces new products to existing markets. 


\section{REFERENCES}

[1] R. Wicaksono, S. Sutardi, and H. Herminiwati, "Pembuatan karet riklim dari ban bekas dengan microwave ditinjau dari karakteristik vulkanisasi kompon," Maj. Kulit, Karet, dan Plast., vol. 20, no. 1, p. 23, Dec. 2004.

[2] B. Karaağaç, M. İnal, and V. Deniz, "Predicting optimum cure time of rubber compounds by means of ANFIS," Mater. Des., vol. 35, pp. 833-838, Mar. 2012.

[3] P. Zhang, F. Zhao, Y. Yuan, X. Shi, and S. Zhao, "Network evolution based on general-purpose diene rubbers/sulfur/TBBS system during vulcanization (I)," Polymer (Guildf)., vol. 51, no. 1, pp. 257-263, Jan. 2010.

[4] S. M. Javadi, M. Moghiman, M. R. Erfanian, and N. Hosseini, "Numerical investigation of curing process in reaction injection molding of rubber for quality improvements," Key Eng. Mater., vol. 462-463, pp. 1206-1211, Jan. 2011.

[5] M.-R. Erfanian, M. Anbarsooz, and M. Moghiman, "A three dimensional simulation of a rubber curing process considering variable order of reaction," Appl. Math. Model., vol. 40, no. 1920, pp. 8592-8604, Oct. 2016.

[6] B. E. Achara, B. S. Mohammed, and M. F. Nuruddin, "Optimisation of nano-silica modified self-compacting highVolume fly ash mortar," IOP Conf. Ser. Mater. Sci. Eng., vol. 201, no. 1, p. 012013, May 2017.

[7] B. S. Mohammed, O. C. Fang, K. M. Anwar Hossain, and M Lachemi, "Mix proportioning of concrete containing paper mill residuals using response surface methodology," Constr. Build. Mater., vol. 35, pp. 63-68, Oct. 2012.

[8] F. Abnisa, W. M. A. Wan Daud, and J. N. Sahu, "Optimization and characterization studies on bio-oil production from palm shell by pyrolysis using response surface methodology," Biomass and Bioenergy, vol. 35, no. 8, pp. 3604-3616, Aug. 2011.

[9] N. Rattanasom, S. Prasertsri, and T. Ruangritnumchai, "Comparison of the mechanical properties at similar hardness level of natural rubber filled with various reinforcing-fillers," Polym. Test., vol. 28, no. 1, pp. 8-12, Feb. 2009.

[10] K. Pal et al., "Effect of fillers on natural rubber/high styrene rubber blends with nano silica: Morphology and wear," Mater. Des., vol. 31, no. 2, pp. 677-686, Feb. 2010.

[11] G. I. Danmaliki, T. A. Saleh, and A. A. Shamsuddeen, "Response surface methodology optimization of adsorptive desulfurization on nickel/activated carbon," Chem. Eng. J., vol. 313, pp. 993-1003, Apr. 2017.

[12] L. Vera Candioti, M. M. De Zan, M. S. Cámara, and H. C. Goicoechea, "Experimental design and multiple response optimization. Using the desirability function in analytical methods development," Talanta, vol. 124, pp. 123-138, Jun. 2014.

[13] V. Vatanpour, M. Sheydaei, and M. Esmaeili, "Box-Behnken design as a systematic approach to inspect correlation between synthesis conditions and desalination performance of TFC RO membranes," Desalination, vol. 420, pp. 1-11, Oct. 2017. 